DOI: http://dx.doi.org/10.20435/1143

\title{
Consolidação da hegemonia político-econômica dos Estados Unidos da América (EUA) em Bretton Woods: visão geral e comentários iniciais sobre desenvolvimento e organização da economia
} mundial

Consolidation of United States of America's (USA's) political and economic hegemony in Bretton Woods:

overview and initial comments about development and the creation of world's economy organization institutions

Gabriel Bittar Domingues ${ }^{1}$ Josemar de Campos Maciel $^{2}$

${ }^{1}$ Acadêmico do curso de Filosofia da Universidade Católica Dom Bosco (UCDB) e bolsista de iniciação científica do CNPq (PIBIC). E-mail: gabriel-b07@hotmail.com

${ }^{2}$ Docente do Programa de Pós-Graduação Stricto Sensu em Desenvolvimento Local da Universidade Católica Dom Bosco (UCDB), do Master in Territorial Development Erasmus Mundus e professor do curso de Licenciatura em Filosofia da UCDB. E-mail: maciel50334@yahoo.com.br 


\section{RESUMO}

Este ensaio é parte de um trabalho de pesquisa mais amplo de investigação dos pressupostos das ideias sobre o desenvolvimento e propõe-se a apresentar uma visão geral sobre os encontros de Bretton

Woods e a possibilidade de que estes tenham sido utilizados como ferramen-

ta para a consolidação da hegemonia político-econômica dos Estados Unidos da América (EUA), no que se refere ao planejamento do período pós-Segunda Guerra Mundial. 0 trabalho se justifica devido à necessidade de estabelecer um olhar crítico acerca da maneira de atuação dos representantes dos países mais importantes nas conferências do evento em questão. Identificou-se que o individualismo foi vitorioso diante de um plano de desenvolvimento mais complexivo, o Plano Keynes, que propunha um desenvolvimento de união mundial no pós-guerra, enquanto prevaleceu um plano que, por vezes, demonstrava prezar pelos interesses dos norte-americanos: o Plano White.

PALAVRAS-CHAVE

\author{
Bretton Woods \\ Economia \\ desenvolvimento
}

\section{ABSTRACT}

This essay is part of a wider effort to research assumptions and pressupositions of development discourse. Its aim is to present an overview of the Bretton Woods meetings and the possibility that they have been used as a tool for the consolidation of political and economic hegemony of the United States of America (USA) with regard to planning the post-World War II period. The work is justified because of the need to establish a critical eye on the manner of operation of the representatives of the most important countries in the conferences of the event in question. It was identified that the individualism was strongly impressive against a more structurally relevant development plan, the Keynes Plan, which proposed a global union development in the post-war while prevailed a plan that often showed cherish the interests of US Americans: the White Plan.

\section{KEY WORDS}

Bretton Woods

Economy

development 


\section{INTRODUÇÃO}

A finalidade deste artigo é abrir uma série de recuperações de documentos e discussões históricas, que legitimam um protagonismo impreciso nas discussões sobre desenvolvimento. Nas conferências de Bretton Woods, aconteceu uma concentração de temáticas geopolíticas em uma legitimação aparentemente científica, que pode ser deceptiva, mas merece um entendimento. É o que se tenta, de forma incoativa, nas páginas que seguem, tendo por base referências bibliográficas acerca do tema e a coleção oficial de escritos de Morgenthau sobre as conferências, Diaries of Henry Morgenthau Jr.

As Conferências de Bretton Woods legitimaram a reivindicação da necessidade de um planejamento da ordem econômica do pós-guerra que, ao menos teoricamente, visasse à possibilidade de desenvolvimento e progresso financeiro para a maioria possível de países. Sendo assim, por iniciativa do país que estava prestes a vencer a guerra, em acordo com a Inglaterra, decidiu-se que representantes se encontrariam para discutir como se daria tal organização.

Tendo em vista que a maior parte do ouro na época se encontrava em Fort Knox, os EUA se encontravam em posição forte, capaz de decidir os rumos da economia. Foram, pois, capazes de sistematizar instituições que lhes servissem no futuro garantindo sua hegemonia não apenas econômica, mas também política.

Os representantes mais destacados no presente trabalho, Harry Dexter White (EUA) e John Maynard Keynes (Inglaterra), tiveram papel principal nas negociações; White propondo um plano que tinha por base o dólar como referência direta ao ouro e no qual as instituições de organização do capital seriam instrumentos para garantir a liberdade de mercado, e Keynes propondo 
o bancor ${ }^{1}$, sua moeda que não existiria fisicamente e seria controlada por suas instituições, fazendo com que política e economia internacionais se conciliassem por meio do estabelecimento de parâmetros autônomos do International Clearing Bank para o funcionamento da troca internacional.

Neste artigo, em primeiro lugar, foi feita uma análise geral do tema, ou seja, o encontro de Bretton Woods é explicado de maneira sucinta: seus motivos, os economistas dos quais se falará no próximo tópico, personagens importantes do evento, além da maneira de White e Keynes enxergarem a conjuntura política e econômica da época. Em seguida, no segundo item, apresentam-se, em perspectiva comparada, as propostas de White e de Keynes para que se possam perceber os interesses que estavam em jogo em Bretton Woods.

Por fim, no terceiro item, é apresentado o problema da ética e da epistemologia, que estava por detrás de toda a discussão; mais do que um embate econômico e social, e talvez justamente por isso, se manifestam também choques de pontos de vista éticos diferentes. Desse momento em diante e levando em conta o que se falou sobre os planos no segundo item, em que é possível perceber a manifestação da ideologia neoliberal em contraponto à ciência keynesiana (que contém também, sem dúvidas, atravessamentos ideológicos), fica clara a forma como Bretton Woods teria servido como expoente do pensamento laissez-faire, no sentido de ter finalizado com a prevalência do Plano White; a partir daí, os órgãos internacionais de reestruturação do pós-guerra, que ainda hoje existem, se pautaram pela ideologia neoliberal, da qual Bretton Woods é uma espécie de berço. Não se pretende, com o presente artigo, explorar os desdobramentos das propostas de Harry Dexter White que se deram no consenso de Washington (BOAS; McNEIL, 2003), nem nas relações entre conhecimento e

${ }^{1}$ Do francês banque (banco) e or (ouro). 
política para a construção da hegemonia norte-americana nas iniciativas e propostas de desenvolvimento através da obra e da ação de Milton Friedman (HARTLYN; SCHOULTZ; VARAS, 1992) e das iniciativas no mínimo curiosas do Banco Nacional da Suécia, criando um prêmio Nobel paralelo em "Ciências Econômicas" (OXHORN; DUCATENZEILER, 1998; NAZMI, 1996; MEIER, 2005).

Esses assuntos fazem parte de uma investigação mais ampla, que não pode ser feita neste espaço, mas que fica aqui anunciada (Ver também BOAS; McNEILL, 2003; CHAN, 2002; FINE; LAPAVITSAS; PINCUS, 2001; HARTLYN; SCHOULTZ; VARAS, 1992).

\section{EXPOSIÇÃO INICIAL DO TEMA}

No mês de Julho do ano de 1944, centenas de pessoas reconhecidas como membros de governos, economistas e cidadãos de importância política de diferentes países reuniram-se no Mount Washington Hotel, em Bretton Woods, perto às montanhas de Washington. 0 lugar presenciava o encontro que marcaria a história da economia no Século XX.

0 principal motivo para tal intento, pode-se dizer, foi a extensão que tomaram os problemas de mercado gerados pela Grande Depressão; dentre eles, podemos citar o então enfraquecido padrão-ouro, a inexistência de cooperação no âmbito da economia internacional e o aumento das tensões transfronteiriças (STEIL, 2013, p. 1). A Segunda Guerra Mundial (II GM) ainda ocorria, mas aos já possíveis (e prováveis) vencedores se fazia necessário planejar o pós-guerra; pós-guerra esse que, olhando para a análise do fim da Primeira Guerra Mundial (I GM) feita por Keynes, poderia se dar com recursos extremamente limitados e crises no sistema econômico.

Há para Keynes acerca da I GM um problema econômico de recursos já definidos, conforme nos mostra a coleção de artigos escritos por ele e organizada por Szmrecsányi (1978, p. 55-59): 
existem recursos que devem ser utilizados na batalha e aqueles que podem ser oferecidos à população e guardados para a posterioridade da guerra, na utilização da reconstrução do país. Não há produção capaz de mudar significativamente a quantidade de nenhum dos dois tipos, pois não há condições para investir tempo e esforços produzindo bens de consumo. Houve por conta disso, segundo o texto, uma espécie de recessão econômica na Europa após a I GM.

White foi capaz de perceber isso, bem como Roosevelt. Ambos souberam tirar proveito desse fato para garantir aos EUA a hegemonia político-econômica pelas portas que se abriram. Harry White, tendo simpatia pela economia planificada da Rússia ${ }^{2}$ (STEIL, 2013, p. 22) e pelos russos, se pôs a tentar ditar um rumo diferente do que seria proposto por Keynes em relação às novas organizações econômicas internacionais ${ }^{3}$, rumo esse reforçado por alguns pontos-chave que foram decisivos para uma consolidação da hegemonia político-econômica norte-americana no cenário internacional e para ajudar a crescer junto com seu país a nação soviética, através da preferência de quota financeira para a reconstrução pós-guerra a ela oferecida pelo $\mathrm{FMI}^{4}$. A organização dos limitados e escassos recursos do pós-guerra da II GM seria ditada, dessa vez, pelos EUA, possuidor da maior parte do ouro na época. White teria afirmado claramente, segundo os diários de Conferência de Morgenthau, a posição de seu país enquanto possuidor dos recursos e usando dessa oportunidade para manipular o mercado.

\footnotetext{
${ }^{2}$ Segundo Steil (2013, p. 22), White tinha o desejo de estudar a economia planificada no Institute of Economic Investigation of Gosplan.

${ }^{3}$ i.e., às instituições que seriam planejadas por ele ou por Keynes.

${ }^{4}$ Steil (2013, p. 290) afirma que a Rússia teria ficado com um crédito de 10 bilhões de dólares, três vezes mais do que seria oferecido como quota aos britânicos.
} 
MR. WHITE: [...] The gold that is in Fort Knox can be used for only one purpose outside the domestic monetary reserves, and that is to buy foreign exchange. That is why the United States is in an enviable position; that is why we are in a powerful position in this Conference; that is why we dominate practically the financial world, because we have the where-with-all to buy any currency we want, you see. If only England was in that position, or any of the other countries, it would be a very different story. (MORGENTHAU JUNIOR, 1944, p. 30).

Alguns dos temas importantes para White residiam, por exemplo, na estrutura e nas instituições de troca internacional e na consolidação de uma política cambial mundial que impedisse a tática de desvalorização de moeda conhecida como "beggar thy neighbours" ${ }^{5}$, assim como em negar o bancor keynesiano que possibilitava uma maior certeza da segurança das relações econômicas internacionais e fazer com que o dólar pudesse ser a moeda de referência internacional, direcionando o peso da balança do comércio exterior a favor dos EUA e teoricamente, também em favor da autonomia e liberdade; consequentemente, entretanto, em detrimento da segurança e boa distribuição ${ }^{6}$. Isso se daria porque o dólar possuía uma forte base de ouro e seria, no novo sistema monetário internacional, a moeda diretamente ligada ao ouro através da organização proposta de um sistema de paridades. Ou seja, tornar-se-ia a referência internacional para o comércio. Por esse e outros motivos Keynes e os britânicos es-

\footnotetext{
${ }^{5}$ Essa política, literalmente traduzida como "transformar vizinhos em mendigos", pode ser entendida como uma forma de "empurrar a miséria para o vizinho". Consiste em desvalorizar o câmbio abaixo do preço da moeda do país vizinho para obter uma maior eficiência marginal do capital com relação às exportações, culminando no aumento momentâneo da riqueza da nação; um dos grandes problemas é que tal política cambial fará com que o vizinho também entre na "jogada”, desvalorizando sua moeda. Dessa forma, surge um jogo econômico de desvalorização no qual ambos acabam perdendo. Keynes também demonstra grande preocupação com essa política.

${ }^{6}$ Estas que ficariam por conta das instituições que se criaria, principalmente do Banco Mundial.
} 
peravam que a moeda usada internacionalmente fosse o bancor. Este não teria o ouro como referência e poderia proporcionar um crescimento mais igual para todos os países e mais favorável para o Reino Unido.

The stage was now set for the two plans to confront each other. On the battlefield of intellectual flair, the Keynes Plan would surely triumph. But they would engage on terrain decidedly more favorable to White, as it was his nation that held the gold, and the only reliable vouchers for gold: U.S. dollars. Ultimately, this was what the rest of the world would need after the war, and Keynes, for all his brilliance, was not King Midas. (STEIL, 2013, p. 153).

Observa-se também, en passant, que o sistema de paridades fixas relativas ao dólar previsto pelo FMI serviria, grosso modo, para a manipulação não somente da economia internacional, mas também da política interna de outros países.

Em sua forma final, o acordo do FMI previa um sistema de paridades fixas em relação ao dólar, que por sua vez teria uma paridade fixa em relação ao ouro (35 dólares por onça troy). As modificações de paridades se dariam apenas para corrigir desequilíbrios "fundamentais", seriam de iniciativa do membro em questão, mas teriam que ser autorizadas pelo FMI. Caso não autorizadas, sujeitavam o membro desobediente a perder acesso aos recursos do fundo ou mesmo à expulsão. (COZENDEY, 2013, p. 34-35).

Dessa forma, controlando os instrumentos de organização internacional do capital e ditando as políticas internas de países por meio do forte poder político que lhe seria assegurado pelo FMI, os EUA poderiam sempre ajustar o mercado a seus critérios e jamais correriam o risco de sofrer algum ato punitivo do Fundo.

Em contraste, o esquema de White previa a possibilidade de que o Fundo fizesse uma recomendação de modificação de políticas aos países superavitários credores, mas pelo sistema de votação, assegurava que o maior credor, os EUA, jamais recebessem uma recomendação dessa natureza contra sua vontade. (COZENDEY, 2013, p. 39). 
A partir das anotações acima, percebe-se como os EUA seriam realmente o mais influente país ligado ao FMI, pois nas entrelinhas teriam poder tanto sobre os países que do Fundo tomassem dinheiro emprestado quanto daqueles que a ele emprestassem. Tanto o Fundo poderia ser utilizado para alterar a política de países credores quanto a de países devedores.

Levando em consideração todo o contexto, o que ainda contribuia para o sucesso desse empreendimento era o fato de que o então presidente Roosevelt não encontraria, por fim, forte resistência para lidar politicamente com Churchill ou Stalin, quando quisesse encetar alguma jogada política como, de resto, foi o caso de reunir as 44 distintas nações no Encontro de Bretton Woods (sabendo-se que as nações menos abastadas não teriam poder de fala, e que seria possível conduzir as maiores no sentido de acordos favoráveis).

No final de 1944, o futuro da Europa estava sendo decidido não somente no campo de batalha, mas também pela firmeza, pela personalidade e pelo choque de ambições dos três líderes aliados: Stalin, Roosevelt e Churchill. Os três trocavam mensagens com frequência e ocasionalmente se encontravam ao vivo. Cada um tinha os próprios interesses nacionais e mundiais. (BLAINEY, 2010, p. 154).

Assim, entende-se a convenção de Bretton Woods não apenas como forma das nações recuperarem-se da crise econômica advinda de tempos passados e reforçada pela proximidade do fim da guerra, mas também como uma maneira de "aproveitar a oportunidade" percebida pelos EUA de manipular a economia a seu favor e a favor de seus aliados.

As White pursued U.S. global financial domination with a zeal not witnessed before or since in the Treasury, it is more than curious that he should here express objection to using such domination to "become the most powerful nation in the world". With whom did White intend the United States to share power? (...) Half of it focuses on the Soviet Union, referring critically throughout to 
American views of the rising rival power. (STEIL, 2013, p. 40).

Isso seria possibilitado de forma mais concreta mediante a atuação do Plano White. Ele seria um instrumento para que os olhos dos governantes não mais se voltassem para o padrão-ouro em si, mas para o novo padrão dólar-ouro, que estaria sob o controle dos $\mathrm{EUA}^{7}$. Sob esse aspecto, é relevante observação de Cozendey segundo a qual a noção de confiança foi fundamental para aumentar a influência do dólar:

Para White, porém, o dólar era uma moeda de ampla aceitação internacional devido ao fato de os agentes econômicos terem confiança em seu lastro de ouro, ou seja, a certeza de que, em última instância, se requisitassem, obteriam o ouro correspondente ao representado nos bilhetes norte-americanos. Seu sistema propunha, portanto, que todas as moedas tivessem uma paridade fixa em relação ao ouro ou a uma "moeda conversível em ouro", ou seja, no seu entendimento, o dólar norte-americano. A mudança de paridades seria excepcional e só poderia ocorrer com autorização do fundo de estabilização. Ao propor o dólar como pilar do sistema como substituto do ouro, porém, White buscava livrar a política monetária norte-americana dos constrangimentos dos fluxos de capital transfronteiriços, automáticos sob o padrão-ouro, enquanto as paridades fixas asseguravam que as demais divisas não criariam, pela via de desvalorização competitiva, constrangimentos por outro lado. (COZENDEY, 2013, p. 33).

Para Keynes, no entanto, a queda do padrão-ouro era um dos pontos mais importantes para uma justa organização dos recursos após o fim da II GM, e isso representava interesses diferentes dos de White: o Plano Keynes era voltado a um esforço para racionalizar e organizar a economia mundial, independente da existência de um produto referente à moeda de troca, e com certo controle do mercado multilateral, de forma a evitar coerções de uns países sobre os outros. Isso será tratado a seguir com mais detalhes.

\footnotetext{
${ }^{7}$ A URSS foi capaz de perceber isso e expressou o desejo que o ouro do FMI ficasse guardado nos quatro países com a maior quota no Fundo, o que faria com que eles também pudessem aprovar empréstimos, mas não obteve sucesso (STEIL, 2013, p. 235).
} 


\section{FORMAÇÃO DE INSTITUIÇÕES EM BRETTON WOODS}

Um dos pontos para ancorar uma boa compreensão das diferenças entre Keynes e White, e a sua transcendência para entender a questão da dinâmica das concepções de desenvolvimento, é a problemática das trocas internacionais ${ }^{8}$ e a moeda de referência ou padrão para a realização destas. Keynes acreditava que a queda do padrão-ouro, e do dólar como moeda principal, abriria espaço para a expansão desenvolvimentista no sentido de não haver mais algo físico barrando o progresso ${ }^{9}$, a saber, recursos limitados em ouro alocados, em sua maior parte, nos EUA. White por sua vez desejava que o dólar pudesse ser a única moeda com paridade em relação ao ouro, e que o ouro pudesse continuar sendo sinônimo de riqueza devido à alta quantia deste armazenada em Fort Knox.

White wanted to make the U.S. dollar, and only the U.S. dollar, synonymous with gold, which would give the U.S. government a virtual free hand to set interest rates and other monetary conditions at will - not just for the United States, but for the world. Keynes wanted to wean the world off gold, and dollars, by creating a new supranational currency, issuance of which would follow principles consistent with an "expansionist" policy. (STEIL, 2013, p. 148).

E ainda sobre a política econômica internacional idealizada por White:

The most important of White's aims, however - the one that would obsess him in the coming years - was very deliberately left unstated: to elevate the status of the dollar to that of the world's sole surrogate for gold, such that cross-border gold movements would no longer have the power to dictate changes in U.S. monetary policy. This would be set entirely at the discretion of American experts, and would be transmitted to the rest of the world by way

\footnotetext{
${ }^{8}$ i.e., importação/exportação; movimentação de capital, serviços e ativos entre nações.

${ }^{9}$ Vale ressaltar também que o Reino Unido já possuía uma dívida com os EUA referente à I GM e estava contraindo outra, nesse período da II GM, o que reforça as evidências de uma balança financeira (i.e., uma maior quantidade de ouro) que pendia em favor dos EUA, comparando com outros países.
} 
of fixed exchange rates. (STEIL, 2013, p. 128).

Keynes via a necessidade de criar uma nova moeda, o bancor, que unificaria os padrões bancário e aurífero, não pertenceria a nenhuma nação específica, e que poderia ser negociada num órgão internacional capaz de regulá-la sem parcialidade, de modo a organizar a distribuição da riqueza no mundo e inviabilizando jogos cambiais como o "beggar thy neighbour", ao qual já se aludiu anteriormente. Uma das características da moeda seria a de não possuir existência física, o que faria com que não fosse possível delimitar quais países a produziriam, democratizando sua criação. Quando, por exemplo, o Banco Internacional percebesse a necessidade de exportação em um país e houvesse outro que estivesse em condições financeiras muito superiores, este deveria passar a comprar os produtos do primeiro, fazendo o mercado funcionar com justiça e desenvolvimento econômico mais multilateralizado.

O órgão pelo qual ocorreriam as transações internacionais seria a Câmara de Compensações Internacionais (International Clearing Union, ICU/International Clearing Bank, ICB). A moeda do país A deveria pagar pela exportação do país B comprando bancor no ICB e movimentando esse bancor no banco do país B, que o transformaria no equivalente em sua moeda nacional. Esse esquema daria poderes de regulação do mercado ao $I C B$, pois as flutuações se tornariam mais preditivas e, pelo fato de o bancor não existir fisicamente e sua quantidade poder ser manipulada a próprio gosto do $I C B$, os países poderiam crescer com uma muito melhor distribuição da renda, pois a atividade econômica não dependeria da quantidade existente de ouro, dólar ou qualquer coisa física limitada e com local definido. Nota-se que, do ponto de vista da imagem de desenvolvimento proposta por Keynes, o sistema poderia ser comparado a uma rede de pontos interdependentes, enquanto que o outro modelo parece mais uma competição de indivíduos em linha simples, puxada por um corredor apenas. 
Aponta Steil (2013, p.143), acerca da ideia de aumentar o desenvolvimento econômico do pós-guerra, no sentido de reconstrução, e as relações de troca, ambos contidos no Plano Keynes: "This unsual asymetry was a reflection of Keynes's central idea that the ICB should be a tool for encouraging the growth of money in circulation globally, and for putting up barriers against monetary contraction".

Já Skidelsky, sobre o Plano Keynes, comenta o manuseio que poderia ser feito em relação ao balanço de importações/exportações no interior do próprio ICB:

0 traço essencial do plano era que os países credores não teriam o direito de 'entesourar' seus superávits, nem cobrar taxas de juros punitivas por emprestá-los; em vez disso, ficariam automaticamente disponíveis como recursos baratos para saques a descoberto pelos devedores por meio do mecanismo de um banco de compensação internacional, cujos depositantes eram os bancos centrais membros da União. (SKIDELSKY, 1999, p. 121).

White, por sua vez, enxergava a possível criação de duas instituições: o Fundo Monetário Internacional (International Monetary Fund, $I M F^{10}$ ) e o Banco Mundial. Caberia ao IMF a realização de empréstimos e oferta de créditos entre países de forma a organizar o sistema financeiro internacional, evitando crises e situações de subdesenvolvimento, de forma que todas as nações ali pudessem ajudar e ser ajudadas; já o Banco Mundial ${ }^{11}$ possuía como intuito o financiamento da reconstrução dos países após a II GM.

Acerca do IMF, Cozendey (2013, p. 42) aponta uma lista de seis itens contidos originalmente no Artigo 1 da Convenção formadora do Fundo; dentre eles, ressalta-se o Art. V: "Fornecer recursos, 'sob as devidas salvaguardas', para corrigir 'desajustes' de balanços de pagamentos sem recorrer a medidas destrutivas

\footnotetext{
${ }^{10} \mathrm{FMI}$.

${ }^{11}$ Originalmente Banco Internacional para Reconstrução e Desenvolvimento (BIRD).
} 
da propriedade". Isso significaria, em outras palavras, o já aqui abordado poder de alterar as políticas de países que tomassem recursos do Fundo. Esse ponto é bastante ressaltado na literatura, ja desde alguns anos (por exemplo, desde OXHORN; DUCATENZEILER, 1998).

O Banco Mundial, por sua vez, focado em reduzir a problemática do pós-guerra, tem em seu Artigo 1 diversas referências à promoção de investimentos, da reconstrução, do desenvolvimento para propósitos produtivos ${ }^{12}$ (COZENDEY, 2013, p. 43) e outros pontos que versavam sobre um mundo reconstruído após a II GM.

Os objetivos do Banco Mundial, no entanto, sanados os problemas deixados a resolver no período proposto, i.e., reconstruído o que deveria ser reconstruído, voltaram-se aos países chamados de subdesenvolvidos desde a posse de Truman; a instituição passou a agir como um aparelho de fomento ao desenvolvimento de países mais pobres. Cozendey (2013, p. 43-44) se refere a tal questão notando que as “[...] menções à guerra deixam inequívocas as prioridades iniciais do Banco, enquanto uma menção pequena aos países menos desenvolvidos abria espaço para o que viria rapidamente a se tornar o foco da atuação da instituição".

As instituições que triunfaram, levando em conta o contexto já apresentado de pressão política e econômica americana, foram as de White. Usando-se ele do fato de estar com a maior quantidade de ouro, i.e., estando em posição superior aos demais países da Conferência, não se apresentaram dificuldades aos EUA para manipular os países a favor de seus interesses, modificando poucas vezes seus planos originais. Já havia uma dominância de tal nação sobre as demais por estar favorecida geográfica, econômica e politicamente; o que ocorreu, então, em Bretton Woods, não foi

\footnotetext{
${ }^{12}$ Isso pode ser entendido como uma forma de escolher as nações que poderiam tomar empréstimos da instituição; sanados os problemas do pós-guerra, também poder-se-ia entender essa condição como orientadora do Banco rumo a seu novo objetivo: auxiliar os países subdesenvolvidos, que seriam os que necessitariam então dessa produtividade.
} 
um grande jogo de mudança das coisas, mas, isto sim, apenas a consolidação da hegemonia político-econômica dos EUA.

O Reino Unido por sua vez, representado por Keynes, também desejava o foco de poder para si, mas Keynes tinha em mente que os norte-americanos detinham tudo de que precisavam para ter esse poder no pós-guerra: ouro, e por isso não enxergava problemas em dividir com os EUA a liderança do pós-guerra.

0 intento keynesiano se deu no sentido de não permitir que os dominassem as relações internacionais, de forma a colocar o dólar acima de tudo, por exemplo. Keynes sabia ainda muito bem que seu povo estava em dívida com os EUA desde a I GM (SKIDELSKY, 1999, p. 124), e que isso não o colocava em uma posição decisiva nas discussões econômicas internacionais, culminando no fraco poder de sua fala em Bretton Woods.

\section{EMBATE IDEOLÓGICO E RESISTÊNCIA A KEYNES}

Permeando tais acontecimentos, esteve a formação de uma ideologia: o laissez-faire (livre-fazer) ou neoliberalismo, que é trabalhado por economistas que se tornam reconhecidos como Ludwig von Mises, Friedrich Hayek e Milton Friedman - este último inclusive cria a famosa frase sobre a inexistência do almoço grátis, presumindo o interesse pelo lucro e maximização como inerente ao ser humano - disseminando tal pensamento. Tal ideologia está ainda em fase de construção e consolidação, e serve muito bem aos interesses dos EUA nesse período, sendo, portanto, o plano de White muito adequado a isso.

Quando aqui se fala de ideologia, é significado do termo o conceito de Althusser (1980, p. 79), no qual “a ideologia representa a relação imaginária dos indivíduos com suas condições reais de existência"; tal definição não é uma decisão arbitrária sobre o conteúdo que se revela pela palavra "ideologia", mas, isto sim, a explicação do significado contido em um conceito althusseriano 
que se utiliza para expor esse item do artigo. Vale lembrar que tal palavra em Althusser carrega consigo ainda o peso da separação entre a ciência e ela mesma (ideologia) (VÁZQUEZ, 1980, p. 22-25).

Esse embate ideológico entre a economia clássica e Keynes, cuja expressão notamos nas diferenças entre o Plano Keynes e o Plano White, tem peculiaridades epistemológicas e éticas que merecem relevo. Keynes nos apresenta a própria ética liberal como uma ética da probabilidade, como já notou Carabelli (1988, p. 5):

These indications of the genesis of A Treatise on Probability show it did not originate as a technical work on the probability theory, but rather as a work of practical philosophy to the field of moral sciences and human conduct.

Enquanto o neoliberalismo parte do ponto de vista do ser humano como um indivíduo que age apenas por seus interesses, seguindo a linha de Hobbes e Adam Smith, Keynes propõe a ética da ação individual e coletiva que se baseia na probabilidade abrangentes, i.e., na não exclusão dos fatores marginais ${ }^{13}$. Os economistas que partem do princípio clássico já trazem consigo o pressuposto, do ponto de vista da ética, do individualismo exacerbado, da ganância inerente ao homem racional maximizador tal qual já é possível enxergar em Smith (1996, p. 74): “Não é da benevolência do açougueiro, do cervejeiro ou do padeiro que esperamos nosso jantar, mas da consideração que eles têm pelo seu próprio interesse".

Keynes entende que a evidência favorável a uma dada proposição requer sempre interpretação. Isto implica a indispensabilidade dos juízos de valor nos argumentos empíricos e o seu envolvimento na estimação pelo investigador da qualidade e significado da evidência. (NUNES 1998, p. 105).

\footnotetext{
${ }^{13}$ Exemplo do funcionamento de uma teoria probabilística abrangente pode ser encontrado na comparação entre o Black Swan de Taleb e uma curva Gauss com uma distribuição normal de eventos prováveis. 0 que fica de fora das bordas da curva, i.e., o "ponto das improbabilidades", pode ser a causa dos piores desastres, das piores crises (BLYTH, 2013, p. 32-35).
} 
E mais: "Concluindo, Keynes visualizava o futuro como uma combinação de elementos certos e incertos, o que estava em oposição com o credo dominante da tendência para a elaboração de previsões" (NUNES, 1998, p. 178). Isso conduz ao entendimento de que não havia em Bretton Woods apenas uma disputa econômica e política, mas também um choque entre pontos de vista éticos diferentes. Frente a tal questão da análise das probabilidades por detrás dos escritos de Keynes, os neoliberais se encontraram, e ainda se encontram, em um dilema do qual se apartam não refutando, mas ignorando:

A resposta racionalista à incerteza suscitada por Keynes tem sido muito simplesmente negar a sua existência. Como escreve Hahn, os argumentos dados por Keynes no capítulo XII da Teoria Geral não têm sido refutados, mas ignorados. (NUNES 1998, p. 178).

Por outro lado, o fato de Keynes enxergar o dinheiro como algo que deveria ser regulado por uma organização internacional pautada em certos fins de bem-estar e presumir que seja absurda a paridade do dólar com o ouro, já que esta serviria apenas para tornar tal moeda superior às demais já que seria ela referência; serviria, portanto, como instrumento de controle de uma nação sobre as outras, desemboca num problema epistemológico: o dinheiro que Keynes enxerga é diferente do que o racionalismo neoliberal propõe, sendo que a paridade sequer é factual, já que ela é também convencionada pelo mercado; a convenção, portanto, pretendia Keynes, deveria ser feita por um sistema que permitisse sua distribuição de forma correta.

A resistência à proposta keynesiana em Bretton Woods, portanto, teve como pano de fundo a ideologia neoliberal para a criação das instituições do Plano White, que se afasta de uma ciência contendora de uma ética coletiva e se aproxima de uma versão individualista do utilitarismo, conferindo aos EUA maior carga de poder político e econômico por pura convenção, já que, epistemologicamente falando, o fenômeno "dinheiro" é uma 
convenção de mercado e Keynes já havia percebido tal fato, bem como certos economistas anteriores a ele.

\section{CONCLUSÃo}

Visando contribuir com o debate acerca da formação das instituições de Bretton Woods e da expressão da ideologia neoliberal em um embate com o keynesianismo e seu impacto sobre a noção de desenvolvimento, este artigo se dividiu em três partes que buscavam apresentar aspectos gerais dos encontros em Bretton Woods, das instituições contidas nos dois planos e, por fim, do embate entre a economia clássica e o keynesianismo.

0 enfoque demonstrativo que se tomou acerca das intenções de Keynes e de White e de suas condições políticas e econômicas foi necessário para a posterior apresentação das instituições criadas. 0 primeiro, que aparece representando um país desenvolvido, mas debilitado pela guerra, que necessitava de recursos devido ao esforço bélico e às destruições subsequentes, e o segundo representando o país que mais continha ouro e que, portanto, mais possuía força em todos os âmbitos para impor seus ideais aos demais.

O primeiro item buscou apresentar a parte contextual dos encontros realizados, os pontos gerais de interesse de ambos os lados e as condições em que se encontravam, sempre com a fundamentação necessária.

Já o segundo item deu foco às instituições de Bretton Woods e às consequências globais almejadas com tais formas de organização por parte tanto do lado que melhor se impôs nas conferências, isto é, de White, quanto do lado que melhor planejou um pós-guerra, mas que não pôde colocá-lo em prática pela falta de condições políticas, isto é, o keynesiano.

0 terceiro item deste artigo teve por intuito mostrar algumas das questões, em um plano geral, com as quais estavam envolvidas 
as discussões de Bretton Woods, a saber: a ética e a epistemologia, que nos permitiram perceber melhor os intuitos de White (aqui entendido como representante de um plano laissez-faire que permitiria, e permitiu, aos EUA, controlar a política de diversos países por meio do controle por ele exercido sobre a entrada e saída de fundos das instituições de reconstrução do pós-guerra) e os de Keynes (que, pelo que se pôde perceber, buscava uma maior integração dos países em torno de um bem comum com o bancor).

A organização do poder internacional se mostrou, por fim, vítima do individualismo que pairava sobre os principais planos econômicos, não somente o whiteano, mas também o keynesiano, apesar de o último ter se demonstrado muito mais frequentemente mais aberto e menos voltado à consolidação de uma hegemonia política e econômica.

Do ponto de vista da construção de um conceito de desenvolvimento, finalmente, o texto que aqui vai, descortina uma sequência de duas imagens rivais, que ainda disputariam a preferência dos construtores das agendas, ao longo do século XX. A primeira, incorporada na biografia e na proposta de Keynes, uma visão em diálogo com bases de pensamento inclusivas do aspecto multilateral e visando a um equilíbrio dos debates éticos em termos mais ou menos igualitários, ou probabilísticos. A segunda, a proposta vitoriosa de White, uma atualização do reducionismo antropológico segundo o qual o ser humano pensa apenas individualmente, e individualmente compete, abençoado por uma mão invisível, que é uma paródia da ideia teológica de providência (MILBANK, 2009) e que, em ultima análise, legitima o intervencionismo e a hegemonia de modelos impostos a partir de protagonistas mais equipados em termos de força de persuasão. A história e a discussão continuarão, mas é preciso mais espaço para a inclusão das dinâmicas sociais e territoriais na definição de modelos geopolíticos de macrogestão e, consequentemente, conceitos de desenvolvimento. 
0 acordo de Bretton Woods pode ser considerado um momento culminante do novo liberalismo, que aceitou e canonizou como ortodoxia o intervencionismo dos EEUU apoiado pelos delegados presentes. Fine, Lapavitsas e Pincus (2001, p. 1) observam que esse acordo entrou em crise profunda, mesmo tendo sido o pontapé inicial para o estabelecimento da legitimação de um intervencionismo operado ao redor das políticas econômicas e que, de fato, problematizou as relações entre hegemonia e soberania entre os EEUU e seus aliados comerciais - aliados por convicção ou por necessidade de se adequarem a medidas avaliadas como economicamente ortodoxas, mas também como promotoras de paz. E como se sabe, a paz anda lado a lado com a aliança com as nações mais fortes.

\section{REFERÊNCIAS}

ALTHUSSER, Louis. Posições II. Rio de Janeiro: Edições Graal, 1980. 165p. v. 17. (Biblioteca de Ciências Sociais, v. 17).

BLAINEY, Geoffrey. Uma breve história do século XX. São Paulo: Fundamento Educacional, 2010. 307p.

BLYTH, Mark. Austerity: the history of a dangerous idea. Nova Iorque: Oxford University Press, 2013. 322p.

BOAS, Morten; McNEILL, Desmond (Ed.). Global Institutions and Development: Framing the World? New York: Routledge, 2003.

CARABELLI, Ana M. On Keynes's method. Londres: Macmillan Press, 1988. 369p.

CHAN, Sylvia. Liberalism, democracy and development. Cambridge, England: Cambridge University Press, 2002.

COZENDEY, Carlos Márcio B. Instituições de Bretton Woods. Brasília: Funag, 2013. 181p.

FINE, Ben; LAPAVITSAS, Costas; PINCUS, Jonathan (Ed.). Development Policy in the Twenty-First Century: Beyond the Post-Washington Consensus. London: Routledge, 2001. 
HARTLYN, Jonathan; SCHOULTZ, Lars; VARAS, Augusto (Ed.). The United States and Latin America in the 1990s: Beyond the Cold War. Chapel Hill, NC: UNC Press Book, 1992.

MEIER, Gerald M. Biography of a Subject: An Evolution of Development Economics. New York: Oxford University Press, 2005.

MILBANK, John. Theology and social theory. Beyond secular reason. London: Doubleday, 2009.

MORGENTHAU JUNIOR, Henry. Diaries of Henry Morgenthau Jr., April 27, 1933-July 27, 1945. 1944. 368p. v. 749. Disponível em: <http://www. fdrlibrary.marist.edu/_resources/images/morg/md1038.pdf>. Acesso em: 10 jun. 2016.

NAZMI, Nader. Economic Policy and Stabilization in Latin America. Armonk, NY: M. E. Sharpe, 1996.

NUNES, M. Jacinto. O pensamento de Keynes. Lisboa: Imprensa NacionalCasa da Moeda, 1998. 227p. (Estudos Gerais - Série Universitária)

OXHORN, Philip D.; DUCATENZEILER, Graciela (Ed.). What Kind of Democracy? What Kind of Market?: Latin America in the Age of Neoliberalism. University Park, PA: Pennsylvania State University Press, 1998.

SKIDELSKY, Robert. Keynes. Rio de Janeiro: Jorge Zahar, 1999. 162p.

SMITH, Adam. A riqueza das nações - investigação sobre sua natureza e suas causas. São Paulo: Nova Cultural, 1996. 479p.

STEIL, Benn. The Battle of Bretton Woods. Nova Jersey: Princeton University Press, 2013. 449p.

SZMRECSÁNYI, Tamás (Org.). John Maynard Keynes: economia. São Paulo: Ática, 1978. 223p. (Coleção Grandes Cientistas Sociais: 6).

VÁZQUEZ, Adolfo Sánchez. Ciência e revolução - o marxismo de Althusser. Rio de Janeiro: Civilização Brasileira, 1980. 177p. (Perspectivas do homem, v. 136). 
